DE DE GRUYTER

OPEN

DOI: 10.1515/jolace-2016-0025

\title{
Reflections from teachers and students on speaking anxiety in an EFL classroom
}

\author{
Songyut Akkakoson, King Mongkut's University of Technology, Thailand \\ songyutbee@gmail.com
}

\begin{abstract}
This paper reports on part of the research project in which instructor perspectives on the role of anxiety in an EFL speaking classroom and anxiety-coping strategies students employ when speaking English have been investigated. The existence of students' speaking anxiety was revealed via a teacher interview. A total of 88 students from the intact classes also responded to an interview form for an analysis of anxiety-coping strategies they utilised when speaking English in class. The qualitative data from both instruments was analysed using the content analysis. The findings of the teacher interview data put forward that students of this study have experienced speaking-in-class anxiety. This anxiety may influence their grades, to some extent. Three factors that may hinder students' development of oral skills emerge, including their lack of self-confidence, having poor English background and having neither intrinsic nor extrinsic motivation to use English. Using the target language as the medium of communication in class is viewed by the teachers as a must in theory, but flexibility is allowed in practice. Moreover, the results of the student interview data show a wide range of strategies employed to deal with anxiety (ie social, affective, meta-cognitive, compensatory, cognitive and memory-related strategies). Social strategies are the most frequently-used techniques. Suggestions for improvement in the overall oral English (ie vocabulary focus, audiovisual focus, self-practice, social focus, auditory focus, meta-cognitive focus, compensatory focus and affective focus) have also been given by the student participants. An increased repertoire of vocabulary is viewed as the most effective tool for such improvement.

Key words: foreign language anxiety, speaking anxiety, oral English, anxiety-coping strategies

\section{Introduction}

In the ever-evolving world of technology and communication, English becomes the language of the technological revolution and the Internet. As a result, more emphasis on communication-orientated language competence has been placed. More and more students in the non-English speaking countries have, therefore, taken communication courses as part of their undergraduate curriculum, preparing for oral competence before leaving the university and entering working
\end{abstract}


circles. However, in an English as a foreign language (EFL) learning environment, affective learner variables, especially personality factors play an important role in students' language learning process either negatively or positively (ÖztÜrk \& GÜrbÜz, 2013). One of these factors is anxiety. Spielberger $(1983$, p. 1) defined anxiety as 'a subjective feeling of tension, apprehension, nervousness, and worry associated with an arousal of the autonomic nervous system'. Anxiety can be divided into three types: trait anxiety, situational anxiety and state anxiety. Dating back to the late 70s and 80s, we will find two seminal papers, Scovel's (1978) and Horwitz, Horwitz, and Cope's (1986), that are influential in the history of research on anxiety in the language learning area. Scovel (1978) identified early conceptualisations of anxiety, which produced conflicting results in relation to the relationship between anxiety and second language anxiety. He claimed that the distinction between facilitating and debilitating anxiety should be made so that accurate experimental results can be received. According to him, facilitating anxiety makes the learner 'fight the new learning task; it gears the learner emotionally for approval behavior', whereas debilitating anxiety encourages the learner to 'flee the new learning task; it stimulates the individual emotionally to adopt avoidance behavior' (p.139). With this, facilitating anxiety helps to motivate learners to take more on challenges, but debilitating anxiety, in contrast, lessens self-confidence of the learners. In their paper, Horwitz et al. (1986) described foreign language anxiety as 'a distinct complex of self-perceptions, beliefs, feelings, and behaviors related to classroom language learning arising from the uniqueness of the language learning process' (p. 128). They constructed a self-report instrument, Foreign Language Classroom Anxiety Scale (FLCAS), which has been adopted by the bulk of later researchers, to draw out responses of anxiety specific to foreign language classroom settings. They further articulated that language anxiety is situation-specific, mainly separate from the other types of anxiety. According to them, the construct of foreign language (FL) anxiety consists of three interrelated performance anxieties: 1) communication apprehension, 2) fear of negative evaluation and 3) test-anxiety. The first anxiety is defined by Horwitz et al. (1986) as 'a type of shyness characterized by fear of or anxiety about communicating with people' (p. 127). The second refers to 'apprehension about others' evaluations, avoidance of evaluative situations, and the expectation that others would evaluate oneself negatively' (p. 128). The third is 'a type of performance anxiety stemming from a fear of failure' (p. 127) to pass elements of assessment. This model has contributed to a number of studies carried out over the past four decades employing measures to identify anxiety over different language skills experienced by different ethnic groups of language learners, in particular, second/foreign language contexts. The findings point to the same direction that FL anxiety is a unique phenomenon and largely a negative factor in the language learning process (Liu, 2007). 
Realising the importance of anxiety as one of the factors influencing oral communication performance, later researchers have examined the role of anxiety in Asian language learners' speaking as well. For example, Liu (2007) studied anxiety in oral English of non-English major students in China, using the modified FLCAS. This researcher found that a large number of student participants experienced anxiety when speaking English in the classroom. They said that the most anxious moment was when being asked to speak or give presentations in front of other students while the least was during doing pairwork activities. They reported a lot of sources of anxiety such as limited vocabulary, low English proficiency and disassociation of memory. They also said that they could not solve their anxiety problem. Inthakanok (2009-2011) used the FLCAS to examine speaking anxiety of 28 Thai EFL university students. What he found was that generally, these students were in the middle anxiety category. Those who were high anxious students reported that audience and grammar/accuracy were their most frequent sources of anxiety, followed by lack of self-confidence, past experience and English attitudes. Subași (2010) explored two potential sources of the anxiety of Turkish learners of English in oral practice: 1) an individual student's fear of negative evaluation, and 2) his/her self-perceived speaking ability. A 55-item multiple-choice survey was administered to 55 first year students of Anadolu University. Another 15 students were also randomly chosen to conduct an interview in order to find out their reasons for being anxious in using English. The results indicated a positive correlation between an individual's fear of negative evaluation and his/her anxiety level. Mak (2011) investigated factors leading to the speaking-in-class anxiety of a group of 313 Chinese ESL first-year university students in Hong Kong. Based on the data from the FLCASs, it was found that there are five factors contributing to speaking anxiety in the classroom which include speech anxiety and fear of negative evaluation, uncomfortableness when speaking with native speakers, negative attitudes towards the English classroom, negative self-evaluation and fear of failing the class/consequences of personal failure. Heng, Abdullah, and Yusof (2012) administered the adapted FLCASs to 700 Malaysian undergraduate students to explore their English-speaking anxiety experience. These researchers found that most of the students experienced a medium level of oral communication apprehension, test-anxiety and fear of negative evaluation. They further put forward that anxiety forms an important element that could determine language learning success. Sadeghi, Mohammadi, and Sedaghatgoftar (2013) explored speaking anxiety among Iranian female EFL learners by utilising the FLCAS. They found that 22 out of 38 female learners experienced anxiety, whereas 14 of them were found to be high-anxious learners. The researchers concluded that socio-cultural factors were recognised as the factor evoking anxiety among those female students. ÖztÜrk and GÜrbÜz (2014) examined the level, major causes, determining factors of foreign language 
speaking anxiety and perceptions of the anxiety of 383 Turkish university students. The researchers found that the students experienced a low level of EFL speaking anxiety. Most of them thought that speaking skill is an anxiety-evoking factor. Moreover, pronunciation, immediate questions, fears of making mistakes and negative evaluation are the major causes of EFL speaking anxiety.

Given the review on how anxiety phenomenon comes into play in second/foreign language learning, this study reflects on speaking-in-class anxiety through the perspectives of Thai teachers of English and Thai EFL undergraduate students in a normal language learning context. Some pedagogical implications will be discussed for second/foreign language instructors when trying to promote a low-anxiety speaking classroom. Moreover, some suggestions will be given in order to help students to decrease anxiety and boost more confidence in speaking English in class, thus, at last, enhancing their oral English learning.

\section{The Project}

Four intact classes of 88 non-English undergraduate students enrolled on the English Conversation Course in a Thai university in Bangkok were invited for the study. Coming from different departments of science and technology disciplines such as engineering, architecture and applied science, these students met once a week for the lesson, which lasted 180 minutes per week. Moreover, three Thai instructors of English who have more than 10 years of teaching experience participated in the research. One held a Master's in Communication while the other two had PhDs in Language Education and Applied Linguistics respectively.

Research instruments employed were Instructor Interview Form (IIF) and Student Interview Form (SIF). Designed for interviewing the instructors in person with permission to be videotaped, the IIF was employed to gather the instructors' opinions on their students' English speaking anxiety. The complete form comprised four questions:

1) Do you think your students experience speaking anxiety in class?

2) How may speaking anxiety impact on students' grades?

3) Do you think some students have a hard time speaking English in class?

4) Why do you find it important for students to speak the target language in the classroom?

Designed as a written response form, the SIF was used to gather student perceptions of anxiety-coping strategies and suggestions for mastering oral English. Two questions were included:

1) How do you cope with your anxiety when speaking English in class?

2) What is the best way that can help you to speak English better? How will you help yourself (eg being well prepared for the class in advance or studying conversation models in the textbook before the class)? 
The data collection procedures of this study started with designing and constructing the research instruments (SIF and IIF), followed by translating them into Thai. The Thai versions were then reviewed and verified by three colleagues for clarity. The modified versions were based on all suggestions and comments received. Before the course ended, a distribution of the SIFs was made as written response forms for out-of-class assignments to get feedback from the students. The instructor interviews, asking prepared questions in the IIF were conducted by the researcher himself after the course ended. The qualitative data from both instruments was analysed using the content analysis-being collated according to similarities and put in percentage terms. The coding of the data was validated by three experts in the field of Applied Linguistics using the index of item-objective congruence (IOC) test. As a result, items on both research instruments scored greater than 0.50 , consistent with expert judge validity. Comments given by the participating instructors and students were also extracted to include in this report.

\section{Results and discussion}

\section{Instructor interview question number 1}

The question number 1 in the IIFs asks whether teachers think their students have speaking anxiety in class? The information gathered is shown in Table 1.

Table 1: Instructors' opinions on students' in-class speaking anxiety

\begin{tabular}{ll}
\hline Agreeing & Comments \\
\hline $3(100 \%)$ & Instructor 1 \\
& Yes, of course. Anxiety lessens their ability to speak. Most of them \\
& have speaking anxiety. This is obvious when they take a speaking \\
& exam. But in the classroom, I'm not sure whether they don't wanna \\
& say things or they are nervous. It's kind of our points of view. We \\
& don't know for sure whether they have got anxiety or not. We don't \\
& see their hands shaking when they speak English. When I posed \\
& them a question, they heard what the first peer answered. They \\
& had some time to think what to say when it's their turn. The \\
& questions are not hard ones, just those from the textbook, \\
& concerning the lessons they have learnt. I couldn't notice their \\
& anxiety obviously in class. Just feeling that if I don't push them to \\
& say something, they'll just keep quiet. I can just say some of them \\
& had anxiety but not obviously shown. No one couldn't answer the \\
posed questions as they learnt those questions in the textbook \\
earlier. I think if I ask them to say something impromptu, they will \\
be anxious for sure. But if a question is from the learnt lessons, I \\
don't think they feel any nerves. But if other things out of the
\end{tabular}




\begin{tabular}{|c|c|}
\hline & $\begin{array}{r}\text { Journal of Language and Cultural Education, } 2016,4(3) \\
\qquad \text { ISSN 1339-4045 (print), 1SSN 1339-4584 (online, } \\
\text { SlorakEdu, } 0.2\end{array}$ \\
\hline & $\begin{array}{l}\text { textbook context, things that they don't know, I think maybe they } \\
\text { will be nervous. }\end{array}$ \\
\hline & Instructor 2 \\
\hline & $\begin{array}{l}\text { I think yes it affects them. Even those who are efficient, when they } \\
\text { come to talk to me in person, or when being tested, they are kind } \\
\text { of getting nervous and can't think of the answers. As a result, their } \\
\text { production is not as good as it should be. But when they are } \\
\text { relaxed, they are kind of fluent and accurate. In a later class, I asked } \\
\text { why they couldn't answer my questions in the test even though I } \\
\text { asked them a follow-up question from the answer they previously } \\
\text { gave me. They said they were nervous. In the moment of testing, } \\
\text { they said they couldn't think of the answers. I told them next time } \\
\text { in the final test, they needed to be calm down; or else, they } \\
\text { wouldn't be able to do a good job. }\end{array}$ \\
\hline & Instructor 3 \\
\hline & $\begin{array}{l}\text { Yeah, it's obvious when they were being tested. Like my test } \\
\text { comprised } 3 \text { parts: 1) a prepared conversation in pairs, 2) } \\
\text { describing unseen pictures but similar to some in the textbook and } \\
\text { 3) impromptu answering a question randomly selected from the } \\
\text { textbook. Mostly, they did a good job for the first part because they } \\
\text { kind of memorised every single word in the conversation they } \\
\text { prepared in advance. But for the second and the third parts, some } \\
\text { of them just sat still and said nothing. Their faces showed how } \\
\text { nervous and worried they were. Someone was obviously nerve- } \\
\text { wracking. He was kind of shaking and tried to sigh heavily. So, I } \\
\text { tried to comfort them, making them feel less anxious. I also helped } \\
\text { them by dropping some hints and someone could give me some } \\
\text { answers, but others looked worriedly at the pictures and said they } \\
\text { couldn't think of what to say. So, for these students, I think they } \\
\text { feel very nervous when it comes to their speaking test. And for } \\
\text { sure, this anxiety affects their test marks as they can't produce the } \\
\text { language fluently and correctly. }\end{array}$ \\
\hline
\end{tabular}

As the above sentences uttered, all instructors were unanimous in viewing that students experienced speaking anxiety in the classroom setting. This may be said that speaking can be an anxiety-evoking factor in students' language learning process. This result parallels several studies which find that speaking is a factor contributing to anxiety (eg. Liu, 2007; Inthakanok, 2009-2011; Subași, 2010; Mak, 2011; Heng, et al., 2012; Sadeghi, et al., 2013; ÖztÜrk \& GÜrbÜz, 2014). The codes 'This is obvious when they take a speaking exam.'; 'Even those who are efficient,..., when being tested, they are kind of getting nervous and can't think of the answers.' 
and 'Yeah, it's obvious when they were being tested.' further indicate that students get more nervous being tested in the speaking exams than in their normal speaking classes. Because the foreign language anxiety here is about performance evaluation within an academic context, test-anxiety (one of the three performance anxieties conceptualised by Horwitz, et al. (1986)) becomes a dominant performance anxiety experienced by the students in the teacher interviewees' classes in this study. These students may consider speaking English at this stage as their classroom activities involving their performance assessment, rather than as communicating with foreigners through English. Horwitz, et al. (1986, p. 128) further put forward that '[s]tudents who are test-anxious in foreign language class probably experience considerable difficulty since tests and quizzes are frequent and even the brightest and most prepared students often make errors'.

\section{Instructor interview question number 2}

The question number 2 in the IIFs asks how the instructors think speaking anxiety may affect students' grades. Table 2 shows the results.

Table 2: How speaking anxiety may affect students' grades

\begin{tabular}{|c|c|}
\hline \multirow{20}{*}{$\frac{\text { Agreeing }}{2(66.66 \%)}$} & Comments \\
\hline & Instructor 1 \\
\hline & I don't think it affects much as the full marks for speaking tests is \\
\hline & not a very large percentage, just $40 \%$. Those students who have \\
\hline & been good at English since they learnt the fundamental courses \\
\hline & are still good in this course. I asked who the number 1 of the class \\
\hline & is. Their peers still mentioned the same guy who got straight A's \\
\hline & from both English I and II foundation courses. Those who got low \\
\hline & grades from those basic courses, they are still poor in this \\
\hline & conversation course. Those who are good at English, I think they \\
\hline & have got less anxiety than those who are poor at it. \\
\hline & Instructor 2 \\
\hline & Yes. In fact, we can't measure the level of their anxiety. Although \\
\hline & $\begin{array}{l}\text { they are nervous, we won't reduce their scores. But the problem } \\
\text { is that their nerves make them unable to produce the language }\end{array}$ \\
\hline & Or it makes them unable to understand my questions. Then, they \\
\hline & can't give answers. That results in their marks. Although I know \\
\hline & that English of this particular student is good, but if he just gives \\
\hline & the wrong answers or can't give the answers at all, we can't give \\
\hline & him or her a mark. I felt pity for those students who were in this \\
\hline & $\begin{array}{l}\text { situation. In fact, they would have got a better mark if they hadn't } \\
\text { been nervous. }\end{array}$ \\
\hline
\end{tabular}


Instructor 3

Of course, to a certain extent, it affects. Anxiety makes them nervous and they cannot successfully deal with answering the test questions or show the instructor how well they can communicate using English. But I think it's kind of problemsolving. As they are sci-tech students, I think if they have an idea that speaking English is a kind of problem-solving, they may not feel nervous in the test. I always try to instil this concept in class, asking students to imagine that they are figuring out a problem in the oral test, not being tested. But not sure whether they get my point. However, the speaking test is just part of the assessment. Marks from other kinds of tests and assignments may help them to pass the course. But they may not get good grades like A or B+.

The above utterances suggest that speaking anxiety may affect students' grades, to a certain extent, but not totally. One instructor pointed out that students' good language background still plays its role when it comes to being tested. However, although students may get low marks from the oral performance tests because of their test-anxiety, this does not mean they will fail the course. This is because in this formal foreign language learning setting, the evaluation scheme of this course comprises various appraisal aspects, namely midterm and final oral test (36\%), aural test $(18 \%)$, language test $(18 \%)$, course project $(15 \%)$, attendance (5\%) and class participation (8\%). All of these account for $100 \%$ of the total mark. Since the largest portion of the test scores is not solely from speaking tests but other scores the students may gain from other tasks, this may make the total surpass the fail criterion.

\section{Instructor interview question number 3}

The question number 3 asks why the instructors think some students have a hard time speaking English. The information obtained is shown in Table 3.

Table 3: Instructors' opinions on students' hard time speaking English

\begin{tabular}{ll}
\hline Agreeing & Comments \\
\hline $3(100 \%)$ & $\begin{array}{l}\text { Instructor } 1 \\
\text { Yes, it's hard for students to speak up in English. I think this is } \\
\text { because students have never spoken English without having the } \\
\text { textbook at hand. They are kind of accustomed to having the } \\
\text { textbook with them to consult it all the time. When they see } \\
\text { example questions in the textbook, they just try to look at the }\end{array}$ \\
\hline
\end{tabular}


unknown words' meanings. They don't take it in turns asking the questions and giving answers like a normal conversation. They will complete the task by writing the answers and then speaking according to what they have written. Although I try to tell them not to do so as in a real conversation we have no time to write things down first. This is not listening-speaking at all. This is reading and writing. I don't know what to do. Sometimes I ask them to say things immediately. But it takes quite long before one says things out. No one dares to speak up. Even in a language game in which they are divided into two teams, they hardly speak up. Sometimes I time how long it takes before a student says. Like it took 3-4 minutes to speak just one sentence. Sometimes, someone is reluctant to say, repeatedly asking his peer, checking whether it is the correct word without saying it out.

\section{Instructor 2}

Some are poor students. They have joined the class because they followed other students in his major who chose to study this elective subject. This English Conversation I subject is designated for the students to study by their department. Thus, poor students have to struggle to pass the course. So, the problem is from their poor background. And how if the instructor can't pay enough attention to these students like 50 students in the class? We can't have every single student to practise speaking. Students who can converse are those who get accustomed to me. Actually, I try to complete all the lessons in each unit within 2 hours. Then, in the last hour, I'll ask a group of 3 students to take it in turns talking to me personally. But in the large class of 50 students, I can't do that as while waiting some students will leave the room and be gone. That means they blow their chance of getting more practice. This shows their attitudes of not wanting to participate in any speaking activities. When asking questions in class, I will call on the class to answer. And, it's always the same volunteer who gives me the answer.

Instructor 3

I think students in my classes, they are kind of having neither intrinsic nor extrinsic motivation or interest to gain skills to master the language. This may be because they don't need to use English to survive in this monolingual society. Even though they are students now, the subject content in their fields like engineering, science, or technology is also needed English to 
access to. I read one study saying that engineering students just take a look at the applications or examples in the lessons shown in the engineering textbooks written in English. For this, they don't need the mastery of English at all. They just need to understand some English explaining how to do engineering things. Moreover, at this age, I usually ask these students on the first day of the class what their future plans are. You know, most of them said they had no idea yet. So, don't talk about instrumental motivation. No way are they thinking that English will be helpful in their future jobs or careers! So, without any motivation, they don't see the necessity to learn this language. Also, the English language teaching-learning in Thailand from primary schools, it kind of starts from the grammar. It doesn't follow a natural process of listening-speaking at the beginning stage like that of normal language acquisition. This also makes students stick to the grammatical rules and afraid that if they say some English, that may be grammatically wrong. They end up with not daring to speak English at all.

Based on the above opinions, three factors that may hinder students' speaking English in the classroom can be observed: lack of self-confidence, having a poor background of English and having neither intrinsic nor extrinsic motivation to use the language. The first point of this interview question is put forward by the codes '...students have never spoken English without having the textbook at hand. They are kind of accustomed to having the textbook with them to consult it all the time.' These items reveal that one factor distributing students' difficulties speaking English may be their lack of self-confidence. That is why they stick to the textbook, hoping that it can give them material to speak the language correctly. Self-confidence is defined as 'an attitude that you hold about yourself that allows you to move forward and achieve your goals' (Gruber, 2014, p. 1). Self-confidence takes part in speaking in a foreign language. It can be associated with risk-taking (Oxford, 1999) which is one of the important characteristics of successful learning in a second language. Even though it may be impetuous and too embarrassed to make a mistake, a good language learner-to-be should be prepared to take the risk of being wrong to succeed in L2 acquisition.

The next point is the codes '... poor students have to struggle to pass the course. So, the problem is from their poor background'. It is seen here that one instructor ascribes students' hard time speaking English, despite years of learning English in their mainstream schools, to their language learning background which is not beneficial enough for them. The reason behind this inferiority may be concerning problematic issues of English language teaching and learning in Thailand. According to Choomthong (2014), there is a gap in the country's language policies 
and practices. Though English language teaching policy in Thailand promotes the implementation of the communicative approach (Kwangsawad, 2007), the English language teaching, in practice, revolves on the grammar translation method. In fact, this teaching method relies heavily on teaching grammar and practising translation. Its main focus is on reading and writing, emphasising accuracy rather than fluency while no emphasis is put on listening and speaking skills. Thai (L1) is largely used as the medium of instruction in the language classroom. As a result, a lot of students encounter English in written form only, leading Thai students to be unable to communicate effectively in spoken English.

The last point that should be discussed for this interview question is the codes '...I read one study saying that engineering students just take a look at the applications or examples in the lessons shown in the engineering textbooks written in English...they don't need the mastery of English at all.' and '...at this age, I usually ask... what their future plans are..., most of them said they had no idea....No way are they thinking that English will be helpful in their future jobs or careers!' As the codes describe, students' oral communication difficulties may be originated from a lack of motivation which could make them determined to master the language. As Thailand is generally a monolingual society where English is mainly used among a small group of people in the international context, intrinsic and extrinsic motivation of these adolescent students may have not yet arise. However, since the use of English tends to expand into a larger group of people, not only for international relations but also for education, business and industry development, exchanges, entertainment etc; letting students be aware of this may help to raise their motivation. As Mayer (2003) points out that 'When students are motivated to learn, they try harder to understand the material and thereby learn more deeply, resulting in better ability to transfer what they have learned to new situations' (p.459), letting students have the motivation of speaking is, therefore, very important to teaching English.

\section{Instructor interview question number 4}

Question number 4 in the IIFs asks why the instructors find it important for students to speak the target language in the classroom. The information obtained is shown in Table 4.

Table 4: Importance of speaking the target language in the classroom

\begin{tabular}{ll}
\hline Agreeing & Comments \\
\hline $2(66.66 \%)$ & $\begin{array}{l}\text { Instructor } 1 \\
\text { So, I think in class both teachers and students should use the } \\
\text { target language. It's necessary to some extent. But students have } \\
\text { some problems with vocabulary. For poor students, they then } \\
\\
\text { ask their peers about the right words to speak. But I won't tell }\end{array}$ \\
\hline
\end{tabular}


them the words but I will ask them to ask other students first. Or I ask them to find an unknown word from the Internet. Nowadays most of them have got a smartphone which provides dictionary applications. It's $\mathrm{OK}$ for them to kind of switch between L1 and L2. But for efficient students, it's necessary for them to speak English in class. When students don't know the words, I ask them to use the dictionary. And the textbook itself provides some glossaries and also the conversation models. Students can follow or adjust them for their own use. Another problem is that they try to speak English, but I don't understand what they are trying to convey. So I ask them OK to speak Thai. They hardly ever ask me the meanings of words. I usually ask them to practise speaking after model conversations in pairs and then report what his pair did using the third person pronoun. However, they can do this because they tend to write the answers first and then read them to me. They don't just say things spontaneously, but they just read what they have written. I tell them this is not speaking, but it is your reading your written words aloud. They tend to translate their Thai answers into English. They all are likely to do like this. Not just students in some of my sections but in all sections. I'm kind of surprised why they need to write the answers first. Sometimes I ask them to just list some keywords and say things based on them. But they don't they just write the answers in sentences. But there are only a few good students who don't write the answers but say things right away. But most good students also write the answers as well.

\section{Instructor 2}

Yes, I think it's important to use English in class. I believe that input matters a lot to students. In a conversation class, if they have no chance to listen to what we speak in English, words that we use, they may not get the target language. If we just let them study the textbook by themselves and we explain some points, I don't think that will work. Input from the instructor is important. And it's also important for students to speak English. But it's kind of hard to say that they can produce the real English. One of my sections contains half EP students and half ordinary students. Based on the speaking test, many students did a good job but some were poor. But the other two sections are of Prachinburi Campus. Most of them feel awkward about speaking up. When being asked a question, they couldn't answer at all. That is, they can't really produce the language. I asked them to tell me what 
they wanted to say but in English. They said they wished to, but they couldn't. But by the way, they need to practise speaking English. For me, I'm OK if they say both Thai and English in a sentence. This is because I think I'd like to teach a conversation course that doesn't make students get stressed to use the target language. So I try to be as friendly as possible. They can do anything but try to communicate. If they can't really do, I ask them just to speak that in Thai, I will help translate it into English for them. But they don't kind of speak Thai all the time. They try to use English. But the important factor is the number of students in the class. One class contains 50 students. That's impossible to do so.

\section{Instructor 3}

I think so too. Since the course is about English conversations, the medium for teaching-learning should definitely be the target language. I think in an EFL context like Thailand, the only chance for these students to be able to use English is in the classroom. When they are outside, they communicate with others using their L1, Thai. Not much English is used in their daily life. They may find something in English like from ad banners on the roadsides, English newspapers, radio programmes, cable TV programmes, Hollywood films, information on websites. However, as far as my teaching experience is concerned, I don't think most of these students will spend their time outside the classroom exposing themselves to English. So, in theory, I think they should be getting accustomed to both listening to and speaking English in class as much as possible. They should also be encouraged more to expose themselves to the language outside the classroom. However, in practice, most of them still think that speaking English means translating Thai into English word for word. When asked a question, they kind of think of things to say in Thai and try to translate them into English before saying. It seems that they are unable to recognise equivalent words. So they need to have an e-dictionary with them all the time to look the words up. Many of them kind of mix both English and Thai words in a sentence when answering the instructor's questions. I keep telling them that speaking is not at all translating and encourage them not to translate words, but they should construct English sentences instead. One thing is the fact that there are a lot of students in one class. As a result, not every 
student can practise speaking English in class. However, this is a matter of institutional policy.

Based on the above interview scripts, it can be seen that all the three instructors agree that in theory, using the target language in an English conversation class is of necessity. The instructors view that input in the target language is important as living in an EFL context like Thailand, the only chance for students to be able to use English is in the classroom. If they have no chance to listen to what people really say in English or particular words people use, they may not get the target language. However, in practice, there are some exceptions. For poor students, it is acceptable to switch between L1 and L2, but efficient students should use English all the time in class. For those who try to convey English messages but incomprehensible, using L1 is allowed. It is acceptable to say both English and Thai in one sentence. The codes 'For me, I'm OK if they say both Thai and English in a sentence. This is because I think I'd like to teach a conversation course that doesn't make students get stressed to use the target language.' are seen as a remarkable reason for reducing speaking-in-class anxiety. This is consistent with the finding of Mak (2011) who has found that allowing her Chinese learners to use their L1in the ESL classroom helps to reduce their speaking anxiety. She posits that:

...the use of the L1 will build up learners' confidence and, in turn, encourage speaking. Teachers of all languages should, however, note that the amount of L1 to be used should only be enough in order to ensure that adequate exposure to the target language also takes place. (p. 212)

According to her, over-dependence on L1 is not recommended and the level of L1 use should be decreased steadily when learners' second/foreign language confidence and skill increase. Moreover, the interviewed instructors in this study also mentioned some other factors that do not allow a genuine English-speaking atmosphere in class. These involve a limited vocabulary, a culture of translating Thai words into English before reading aloud the words/sentences that have just been written, inability to express ideas, too many students in one speaking class and lack of enough exposure to the target language.

\section{Student interview question number 1}

As witnessed by the instructors that their students have experienced speaking anxiety in class, 88 students were then asked (question number 1 in the student interview form) to reflect on what strategies they used to cope with their anxiety when speaking English in the classroom. Totally 104 responses were given. Table 5 below shows the results obtained. 
Table 5: How the students cope with their anxiety when speaking English in class

\begin{tabular}{l}
\hline Responses \\
\hline Total \\
\hline Social strategies \\
- Speaking English more often-with peers (in class), with \\
foreigners (at sightseeing places, through social networking \\
sites), with oneself (alone at home or when being free, trying \\
putting on a native speaker accent, speaking based on \\
instructions from the Internet or books on how-to-speak \\
English). \\
- Trying to have fun with the class by participating in the \\
classroom activities. \\
- Speaking what you have prepared to peers first so that they \\
could help make corrections. \\
- Speaking English with a close friend or the one whom you \\
are acquainted with.
\end{tabular}

\section{Affective strategies}

- Trying to reduce anxiety, trying not to get nervous, thinking positively that I can do it.

- Speaking up loudly to increase confidence and to release the stress.

- Taking the risk of making mistakes, trying to think positively that English is not scary as mistakes can be made.

- Overcoming the fear of speaking to foreigners, thinking that we just experience the way to learn to speak English.

- Leaving out pressure on grammar, just caring about communicable messages.

- Trying to think that speaking English is good fun.

- Keeping calm, encouraging yourself to learn from mistakes for further improvement.

- Imagining that you are speaking an official language that will be used in our neighbouring countries in the future.

- Increasing more self-confidence.

- Appearing natural, thinking that speaking English is not embarrassing.

- Building encouragement in oneself.

- Putting no pressure on oneself, telling yourself to be assertive, telling yourself that it is an experience which helps 
increase your speaking skills, making yourself relaxed not stressed out.

- Keeping thinking that English is not our mother tongue so we can make mistakes.

\section{Meta-cognitive strategies}

- Thinking before speaking something out, thinking of words to say before speaking up.

- Keeping on speaking although making mistakes, saying things as you think without paying attention to making mistakes.

- Keeping on speaking without losing concentration so that we don' $t$ think of anything else.

- Paying more attention to English.

- Being well-prepared before the class, studying the lessons in advance, preparing and practising saying what to speak first.

- Trying to get accustomed to English as much as possible by learning from things in the daily life, exposing oneself to the language, for example, watching English programmes on TV, watching films with English subtitles, listening to and/or singing English songs, reading cooking recipes in English, practising listening more often.

\section{Compensatory strategies}

- Increasing English skills by taking extra courses.

- Increasing your repertoire of vocabulary used in various situations through self-studying.

- Keeping quiet, falling silent, not saying anything.

\section{Cognitive strategies}

- Reading a lot of model dialogues in the textbook, reading English texts a lot more.

- Practising English pronunciation.

- Practising making English sentences.

- Paying attention to the questions posed and answering them with understandable details.

\section{Memory-related strategies}

- Regularly revising the lessons learned.

- Remembering and recalling vocabulary regularly.

Once the anxiety comes into view, the student participants deal with it by using a wide range of anxiety-coping strategies. These strategies can be related to Oxford's (2003) classification of language learning strategies. The most frequent 
strategies used are social strategies (35.57\%). This is quite expected as social strategies lead to increased interaction with the target language by asking questions, co-operating with others, or empathising with others. Here is an excerpt from one student who said: 'I practise speaking English with a close friend or the one whom I am acquainted with.'

The second most frequently-mentioned coping strategies fall into the category of affective strategies (21.15\%). These strategies are concerned with the learner's emotional requirements such as lowering their anxiety, encouraging themselves, or taking their emotional temperature. Some statements from one interviewee represent this category: 'I try to reduce anxiety and try not to get nervous. I think positively that I can do it.'

The next category in the order contains meta-cognitive strategies $(19.23 \%)$ which help learners to regulate their learning (eg centring their learning, arranging and planning their learning, or evaluating their learning). One participant confirmed using strategies of this category as follows:'I try to be wellprepared before the class. I study the lessons in advance. I prepare and practise saying what to speak first.'

The third runner-up falls within the category of compensatory strategies $(13.46 \%)$. These strategies assist learners in overcoming knowledge gaps to continue the communication (eg guessing intelligently, or overcoming limitations in speaking and writing). One student mentioned: 'I try to increase my repertoire of vocabulary or words that are used in various situations through my self-studying.'

At the bottom of the list, two categories of less frequent strategies were reported, cognitive strategies and memory-related strategies. The former includes mental strategies learners use to make sense of their learning, for example practising, receiving and sending messages, analysing and reasoning, or creating a structure for input and output. One participant said: 'I pay attention to the questions posed and answer them with understandable details.'

The latter includes those utilised for storage of information, for example creating mental linkages, applying images and sounds, revising well, or employing action. Another participant said: 'I regularly revise the lessons I have learned.'

The above results partly support those of previous researchers. First, the students in Woodrow's (2006) study referred to the following strategies they employed to deal with second language speaking anxiety: affective strategies (eg not giving up when speaking, positive self-talk, deep breathing and conscious efforts to calm oneself), meta-cognitive strategies (eg preparing utterances and studying to improve speaking) and compensation strategies (eg smiling and volunteering 
comments). Another similar match is found in Liu's (2007) study. Her students reported that their coping strategy was trying to tell themselves not to be nervous before speaking English in class, which is also one of the affective strategies found in the present study. Next, the students in Inthakanok's (2009-2011) study reported employing four main anxiety-coping strategies, namely planning/practising, using other means of communication, teacher/other people correction/evaluation and avoidance of speaking. What can be similarly matched here are 1) his planning strategy which is one of the meta-cognitive strategies in the present study; 2) his practising, one of the cognitive strategies; 3) his teacher/other people correction/evaluation, one of the social strategies and 4) his avoidance of speaking and using other means of communication, those of the compensation strategies. Moreover, Zhiping and Paramasivam's (2013) students reported two types of strategies for coping with anxiety, namely compensatory strategies (eg keeping silent, avoiding eye contact, expressive reactions) and social strategies (eg being with friends).

\section{Student interview question number 2}

The question number 2 in the interview form asks the interviewed students what they think is the best way to help towards speaking English. Totally 156 responses were collected. Table 6 below details the results.

Table 6: Suggestions for making improvements in speaking English

\begin{tabular}{ll}
\hline Responses & Frequency (\%) \\
\hline Total & $156(100 \%)$ \\
\hline Vocabulary focus & $56(35.84 \%)$ \\
- Study vocabulary or new words every day./Memorise and \\
$\begin{array}{l}\text { recall vocabulary regularly./Have a dictionary at } \\
\text { hand./Collect unknown words in a diary. }\end{array}$
\end{tabular}

\section{Audiovisual focus}

- Watch soundtrack films, or American TV series with English subtitles, or with no Thai subtitles./ Watch English cartoons./Watch VDO clips teaching how to speak English.

\section{Self-practice}

- Speak or talk to yourself alone in English./Keep on practising speaking English to yourself more often./Try to speak in natural contexts which may result in unconscious learning how to speak English naturally. If we put it in leaning contexts, we will be under pressure to pass the exams./Experience speaking English by the process of trial 
and error./Practise speaking, reading and writing 10 English sentences daily./Practise English regularly using a lot of methods.

\section{Social focus}

$17(10.89 \%)$

- Speak to peers in English more often./In class, talk to peers in English. Anyone who accidentally speaks Thai, they will be fined some money./Practise speaking English with Thai friends in various daily life situations./Simulate real-life situations in the classroom./Experience speaking in a real situation./Join the in-class conversations and roleplay/real life situations./Speak to foreigners as much as possible./Try to find foreign friends and speak to them./Follow the lessons the instructor taught and apply using them.

\section{Auditory focus}

- Listen to English songs and reading their lyrics along and consulting a dictionary for those unknown words found./Try to listen to and remember conversation models and apply them to other situations./Listen carefully and grab the main ideas./Practise listening to the coursebook CD.

\section{Meta-cognitive focus}

- Study the lesson content and model conversations in the textbook in advance and revising the lessons after the class./Study related grammar in advance./Study English sentence structures./Study language functions.

\section{Compensatory focus}

- Take extra courses in English speaking.

\section{Affective focus}

$1(0.64 \%)$

- Dare to speak up.

As shown in the table, the majority of respondents think that increasing a repertoire of vocabulary would help them to improve their oral English (35.84\%). They believe that memorising and recalling vocabulary regularly, or having a dictionary at hand would help them to speak English better. $16.66 \%$ of the respondents view that audiovisual material would be a good source of language exposure. They agree with watching films with English subtitles or with no Thai subtitles, or American TV series. 14.74\% of the respondents view that having recourse to self-practice would be the best way of oral English improvement. They 
think that if one keeps practising speaking English to oneself, that would help. $10.89 \%$ of the respondents confirm that the best way is to depend on social interaction. They suggest trying to find someone to talk to in English. Moreover, $10.25 \%$ of them think that any practice that relates to improving listening skills would help, for example listening to English songs and trying to understand their lyrics. If unknown words are found, consulting a dictionary is a solution. Next, $10.25 \%$ of the respondents mention that realising one's own thinking process could be another way to help. This may include studying the lesson content together with its model conversations in the textbook in advance and revising things learnt after class. The last two resources involve finding something to assist learners in overcoming knowledge gaps $(0.64 \%)$ and using learners' emotional aspects to help $(0.64 \%)$. These may include taking an extra course in oral communication, or building up one confidence in speaking English.

\section{Conclusion}

The present study reflects the existence of speaking-in-class anxiety through the perspectives of Thai teachers of English and Thai EFL undergraduate students in a normal language learning context. EFL speaking anxiety experienced by the students in this study was revealed via a teacher interview. A total of 88 students from the intact classes also responded to an interview form for an analysis of anxiety-coping strategies they utilised when speaking English in class. The results of the teacher interview data reveal that the students in this study experience speaking-in-class anxiety. This anxiety may influence students' grades, to some extent. There are three factors that may hinder students' progress or development of oral skills. These include their lack of self-confidence, having poor English background and having neither intrinsic nor extrinsic motivation to use English. Using the target language as the medium of communication in class is viewed by the teachers as a must in theory, but flexibility is possible in practice. Moreover, the results of the student interview data illustrate that a wide variety of anxietycoping strategies has been employed (ie social, affective, meta-cognitive, compensatory, cognitive and memory-related strategies). Social strategies are the most frequently-used techniques. The students believe that vocabulary focus, audiovisual focus, self-practice, social focus, auditory focus, meta-cognitive focus, compensatory focus and affective focus would bring about an improvement in their oral English. Vocabulary repertoire is reported as being the most helpful method. These conclusions give guidance on how teachers and students to deal with speaking anxiety in the EFL classroom. EFL teachers should identify students having anxiety over oral production and low self-esteem, seek for the appropriate strategies to assist students in decreasing or eradicating anxiety and build up a pleasant and encouraging classroom environment for them to practise the target language. 
To identify anxiety, first and foremost, teachers ought to know who their students are in order to take precautions against anxiety. Students' background information, for example individual details, educational background, levels of English proficiency, should be learned of. A mini-survey using the classic instrument like the Foreign Language Classroom Anxiety Scale (FLCAS) developed by Horwitz, et al. (1986) can be used at the beginning of the course in order to identify and measure the level of anxiety students may have. Moreover, students should be encouraged to share their feelings with other classmates. If they find that other students are also nervous about speaking English, they might feel more relaxed in the classroom as they would realise that both their other peers and their teacher empathise with them.

The following suggestions about teaching strategies may be of benefit to reduce classroom anxiety. As emerging from the teacher interview data in this study, testanxiety becomes a major factor leading to Thai EFL speaking-in-class anxiety, a conventional way of testing students' oral performance individually should be changed. A pair or a group evaluation should be implemented. Following this, more than one student will sit in front of the teacher for an interview examination, resulting in students' decreased fears of being constantly assessed and of anxious moments of oral English performance. An individual's assessment can still be made through teacher observation. In addition, various teaching strategies which have been recommended by previous researchers are worth noting here. According to Mak (2011), teachers should be certain that enough time is given for students to prepare their oral production or presentation and enough wait-time to speak up should be provided for them to deal with a question posed and organise a reply. Immediate questions which need impromptu answers should not be used. The use of learners' L1 in class should also be allowed to reduce speaking-in-class anxiety, but its amount should not extend much beyond the appropriate exposure to the target language. Teachers should create a balance between language accuracy and fluency in class. Using students' mistakes to exemplify linguistic points should be made when the whole class agrees about the focus on accuracy while a focus on fluency with less grammatical strictness would help to establish students' confidence in oral production. Sadeghi, et al. (2013, pp. 127-128) have suggested some useful classroom strategies to lessen students' anxiety as follows:

1) Teachers should try not to correct all the minor performance difficulties of the students while speaking as the classroom is just set for learning, not a real communicative event.

2) Strong criticism of students' accent is not recommended as poor or sensitive students may lose self-confidence and become stressed.

3) The chance to have classroom interaction should be promoted as much as possible, which would lead to a decrease in students' communicative fears. 
4) Groupwork can increase students' motivation, classroom's communicative focus, bravery in making mistakes and confidence in oral production.

5) Teachers should build up a learning community which has a more helpful atmosphere.

6) Students should be encouraged not to be shy or embarrassed about asking the teacher for help.

7) Corrections in students' oral mistakes or errors should not be directly made, but the teacher's prompts should be provided as repair strategies.

8) Students' social image should be protected by keeping their marks a secret and advising the students not to laugh at any peers who make speaking mistakes.

9) Teachers' characteristics should be adjusted to be friendlier, more lively and more outgoing.

10) Both verbal and non-verbal kinds of praise from the teacher should be given as positive reinforcement.

11) Students' ideas of perfect English should be eliminated as speaking by using their limited knowledge of vocabulary and language is acceptable.

12) Teachers should be aware of social-cultural factors that may influence students' confidence in oral production.

Sincere and friendly classroom atmosphere in which students speak English in comfort should be created as well. Liu (2007) confirms that this would help to make students feel less intimidated to produce English utterances. Teachers should first be sociable rather than authoritarian and critical in class. Strict evaluation and critical reactions in the classroom should be got rid of. Students should be made aware of the fact that it is normal to make mistakes while speaking and that learning from their own mistakes is the best way for language learning. Moreover, various classroom activities to help students to break the ice during the first few lessons should be organised. Students should be trained to be friendly to one another in class. This is because competitive atmosphere makes students more worried, whereas friendly relationship causes them to feel more relaxed to speak the target language in class. To change fear into friendliness in the speaking classroom, Stewart and Tassie (2011) have provided some suggestions which are worthy of note here: respecting cultural differences, avoiding instructor bias, using class time for practice and providing an encouraging classroom atmosphere.

EFL students should recognise the existence of oral anxiety in the classroom. Then, they should look for strategies that help to deal with their anxiety. Learners should be well aware of the fact that it is the learners themselves who are mainly responsible for their own learning, thus having to control their own anxiety or minimise or get rid of it strategically (Inthakanok, 2009-2011). The findings of this study provide students with possible anxiety-coping strategies, which could give 
them valuable insights for lessening their own anxiety. These strategies (ie social, affective, meta-cognitive, compensatory, cognitive and memory-related) are worth trying. Furthermore, when it comes to oral test situations held under timed conditions, Heng et al. (2012) have suggested some techniques that could be useful for students to defeat test-anxiety: breathing techniques, physical and mental exercises and early arrival for a test. The amount of success in students' oral improvement also depends on their participation in oral activities in class, which needs their motivation and a good rapport between students-teacher and students themselves in the classroom (Derakhsha, Tahery, \& Mirarab, 2015).

In addition, as reflected in the instructors' opinions in the present study, three factors that may hinder students' progress or development of oral skills comprise their lack of self-confidence, having poor English background and having neither intrinsic nor extrinsic motivation to use English. These three obstacles should be treated with effort and attention. This is because all in all students' oral improvement can be bettered so long as they are driven by a desire to achieve. For making improvements in oral English skills, student participants in this study suggest that EFL students should be concentrating on vocabulary, audiovisual resources, self-practice, interaction with others, auditory practices, metacognitive knowledge, compensatory resources and emotional encouragements. Suggestions from some other researchers are also worthwhile following. Improvement of English proficiency, expansion of vocabulary, having an oral practice of English and getting prepared for oral English lessons are what Liu (2007) has suggested students to do. Woodrow (2006) also suggests that communication outside the classroom is also important for students' oral improvement. However, in the context of English as a foreign language, rich linguistic resources are not available for students to do out-of-class tasks. Shortterm project work such as videotaping an interview with foreign tourists or expatriates can be a good alternative.

The study has some implications for further studies. First, exploring the potential sources of oral production anxiety using different forms of qualitative data collection such as diary writing and think aloud protocols can be conducted. Second, an empirical study should be conducted to see how effective anxietycoping strategies such as those emerging from this study are in English-speaking classrooms. Third, because motivation and anxiety may be related in some way, research into motivation in English-speaking classrooms could also be worthwhile conducting. Fourth, examining the sources of foreign language anxiety for other language skills such as listening, writing and reading would be worthy of doing. Finally, since anxiety levels and anxiety-evoking factors may differ from context to context, more studies should be conducted with various groups of learners in different locations to better understand the construct and promote the learning of oral communication. 


\section{Acknowledgements}

This research was funded by King Mongkut's University of Technology North Bangkok (KMUTNB) under the contract no. KMUTNB-GEN-57-34. Many thanks go to the teacher and student participants in this study.

\section{References}

Choomthong, D. (2014). Preparing Thai students' English for the ASEAN Economic Community: Some pedagogical implications and trends. Language Education and Acquisition Research Network (LEARN) Journal, 7(1), 45-57.

Derakhshan, A., Tahery, F., \& Mirarab, N. (2015). Helping adult and young learners to communicate in speaking classes with confidence. Mediterranean Journal of Social Sciences, 6(2), 520-525.

Gruber, K. (2014, February 19). The Importance of Self-Confidence. Livestrong.com. Retrieved from http://www.livestrong.com/article/ 138172the-importance-self-confidence/

Heng, C. S., Abdullah, A. N., \& Yusof, N. B.. (2012). Investigating the construct of anxiety in relation to speaking skills among ESL tertiary learners. $3 L$ : The Southeast Asian Journal of English Language Studies, 18(3), 155-166.

Horwitz, E. K., Horwitz, M. B., \& Cope, J. (1986). Foreign language classroom anxiety. The Modern Language Journal, 70(2), 125-132.

Inthakanok, I. (2009-2011). Speaking anxiety of a group of Thai EFL university students: Its sources and coping strategies. Journal of Education Silapakorn University, 1-2, 82-101.

Kwangsawad, T. (2007). Bridging the gap between CBT and CBI theories in Thai small rural schools. Proceedings of the 1st International Conference on Educational Reform 2007. Mahasarakham: Mahasarakham University.

Liu, M. (2007). Anxiety in oral English classrooms: A case study in China. Indonesian Journal of English Language Teaching, 3(1), 119-137.

Mak, B. (2011). An exploration of speaking-in-class anxiety with Chinese ESL learners. System, 39, 202-214.

Mayer, R. E. (2003). Learning and instruction. Upper Saddle River, NJ: Pearson Education, Inc.

Oxford, R. (1999). Anxiety and the language learner: New insights. In J. Arnold (Ed.), Affect in language learning (pp. 58-67). Cambridge: Cambridge University Press.

Oxford, R. L. (2003). Language learning styles and strategies: An overview. Proceedings of the Generative Approaches to Language Acquisition Conference (GALA) 2003. (pp. 1-25). Retrieved from http://web.ntpu.edu.tw/ language/workshop/read2.pdf. 
ÖztÜrk, G., \& GÜrbÜz, N. (2013). The impact of gender on foreign language speaking anxiety and motivation. Procedia-Social and Behavioral Sciences, 70, 654-665.

ÖztÜrk, G., \& GÜrbÜz, N. (2014). Speaking anxiety among Turkish EFL learners: The case at a state university. Journal of Language and Linguistic Studies, 10(1), 1-17.

Sadeghi, K., Mohammadi, F., \& Sedaghatgoftar, N. (2013). From EFL classroom into the mainstream: A socio-cultural investigation of speaking anxiety among female EFL learners. International Journal of Society, Culture \& Language, 1(2), 117-132.

Scovel, T. (1978). The effect of affect on FL learning: A review of the anxiety research. Language Learning, 28(1), 129-142.

Spielberger, C. D. (1983). Manual for the state-trait anxiety inventory. Palo Alto, CA: Consulting Psychologists Press.

Stewart, F., \& Tassie, K. E. (2011). Changing the atmos'fear' in the public speaking classroom. International Journal of Humanities and Social Science, 1(7), 9-13.

Subaşi, G. (2010). What are the main sources of Turkish EFL students' anxiety in oral practice? Turkish Online Journal of Qualitative Inquiry, 1(2), 29-49.

Woodrow, L. (2006). Anxiety and speaking English as a second language. RELC Journal, 37(3), 308-328.

Zhiping, D., \& Paramasivam, S. (2013). Anxiety of speaking English in class among international students in a Malaysian university. International Journal of Education and Research, 1(11), 1-16.

\section{Contact}

Asst Prof Dr Songyut Akkakoson

King Mongkut's University of Technology North Bangkok

1518 Pracharat Sai 1 Road

Wongsawang

Bangsue

Bangkok 10800 Thailand songyutbee@gmail.com 